\title{
Alpha- 1 antitrypsin is markedly decreased following pulmonary F. tularensis challenge
}

\section{James P. Chambers ${ }^{1,2 *}$, Jieh-Juen Yu ${ }^{1,2}$, Madhulika Jupelli ${ }^{1}$, Susan T. Weintraub ${ }^{3}$, Jose L. Lopez-Ribot ${ }^{1,2}$, James J. Valdes ${ }^{4}$ and Bernard P. Arulanandam ${ }^{1,2}$}

1 Department of Biology, South Texas Center for Emerging Infectious Diseases, University of Texas at San Antonio, San Antonio, TX, USA

${ }^{2}$ Department of Biology, Center of Excellence in Infection Genomics, The University of Texas at San Antonio, San Antonio, TX, USA

${ }^{3}$ Department of Biochemistry, The University of Texas Health Science Center at San Antonio, San Antonio, TX, USA

${ }^{4}$ Engineering Chemical Biological Command, US Army, Aberdeen Proving Ground, MD, USA

\section{Edited by:}

John S Gunn, The Ohio State

University, USA

Reviewed by:

John T Belisle, Colorado State University, USA

Barbara Mann, University of Virginia, USA

\section{*Correspondence:}

James P. Chambers, Department of Biology, Center of Excellence in Infection Genomics, South Texas Center for Emerging Infectious Diseases, University of Texas at San Antonio, San Antonio, TX 78249, USA. e-mail: james.chambers@utsa.edu
Neutrophils form the first line of defense during infection and are indispensable in this function. The neutrophil elastase is a key effector molecule of the innate immune system with potent antimicrobial activity against Gram-negative bacteria, spirochaetes, and fungi. However, the release of neutrophil elastase during bacterial infection must be checked otherwise its release in the extracellular milieu will result in damage to surrounding tissues. Alpha-1 antitrypsin is a small glycoprotein clade A serpine serine protease inhibitor and has been shown to increase in humans following bacterial and viral infection. Francisella tularensis is a Gram-negative facultative intracellular bacterium and the causative agent of tularemia. Type A strains are the most virulent with an infectious dose as low as 10 colony forming units and a mortality rate of 30-60\% among untreated cases of pneumonic tularemia. We report here significant reduction of this major inhibitor of the neutrophil elastase in plasma of $F$. tularensis LVS and $F$. tularensis (type A) SCHU S4 infected animals following pulmonary challenge. Associated with an imbalance of protease-antiprotease function at the alveolar level in lungs of infected animals, increased elastase activity was observed in lung lavage fluids accompanied by decrease lung function, i.e., loss of lung elastance with concomitant increase of pulmonary hysteresivity. Consistent with a competent acute phase response following $F$. tularensis LVS and F. tularensis (type A) SCHU S4 pulmonary challenge and proposed up-regulation of plasma haptoglobin during the course of the acute phase reaction, haptoglobin was observed significantly increased. These data suggest that unchecked neutrophil serine protease activity may arise from $F$. tularensis targeted reduction of plasma $\alpha_{1}$-antitrysin promoting lung tissue damage facilitating increased dissemination of this bacterium in infected animals.

Keywords: antiprotease, neutrophil, elastase, plasma, lung lavage, Francisella

\section{INTRODUCTION}

Neutrophils are one of the first immune cells to arrive at the site of inflammation. These cells efficiently degrade microorganisms via the action of proteases and oxidant species restricting pathogen replication and spreading at multiple levels, e.g., direct cleavage of virulence factors (Weinrauch et al., 2002), degradation of cytokines (Mezyk-Kopec et al., 2005), modulation of production of chemokines (Geraghty et al., 2007), and tissue breakdown allowing direct contact between immune cells and pathogens preventing bacterial escape (Kielty et al., 1993).

The neutrophil protease elastase is a key effector molecule of the innate immune system with potent antimicrobial activity against Gram-negative bacteria (Belaaouaj et al., 1998), spirochaetes (Garcia et al., 1998), and fungi (Tkalcevic et al., 2000). Because neutrophil elastase has been shown to digest virtually every type of matrix protein, including several types of collagens, fibronectin, proteoglycans, heparin, and cross-linked fibrin (Travis, 1988), tissue digestion is its best-known extracellular manifestation which has its roots in hereditary $\alpha_{1}$-antitrysin deficiency. Thus, elastase is synthesized as a zymogen and requires cleavage by cathepsin- $\mathrm{C}$ to become active and is subsequently stored within cytoplasmic azurophilic granules until extruded into phagolysosomes or out of the cell (Methot et al., 2007). Once released, active elastase is held in check by the protease inhibitor $\alpha_{1}$-antitrysin.

Although named $\alpha_{1}$-antitrysin, the physiologic target is neutrophil elastase rather than trypsin and for this reason it is commonly referred to as $\alpha_{1}$-proteinase inhibitor. Alpha- 1 antitrypsin is a small glycoprotein $(52 \mathrm{kDa})$, clade A serpine serine protease inhibitor which is constitutively made in the liver and released into the blood stream. The archetype of the serpin family and present at highest concentration in plasma, $\alpha_{1^{-}}$ antitrysin is the major inhibitor of extracellular neutrophil elastase (Heutinck et al., 2010). The acute phase response to infection and injury is characterized by changes in serum protein composition. Such changes may give rise to specific response patterns and thus provide information as to the etiology of disease. Alpha- 1 antitrypsin and haptoglobin are acute phase reactants, the 
concentration of which typically increase during the acute phase response.

Francisella tularensis is a Gram-negative facultative intracellular bacterium and the causative agent of tularemia. Type A strains are the most virulent with an infectious dose as low as 10 colony forming units (CFU) and a mortality rate of 30-60\% among untreated cases of pneumonic tularemia (Stuart and Pullen, 1945). The basis of the very infectious nature of inhaled Francisella remains unclear. Neutrophil influx and release of neutrophil-chemotactic chemokines have been observed in the lungs including monkeys, rabbits, rats, and mice (Schricker et al., 1972; Dunaeva and Shlygina, 1975) following respiratory infection. Using an in vitro approach, Moreland et al. (2009) studied the interaction of F. tularensis LVS with pulmonary microvascular endothelial cells. Although F. tularensis LVS interacted with pulmonary cells in a fashion that promoted PMN transmigration, these stimulated PMN did not elicit proinflammatory cytokine release nor was NADPH oxidase activity which generates pathogen reactive neutralizing oxygen species compromised. This is in contrast to earlier studies indicating disruption of normal PMN oxidative function following ingestion of Francisella (Lofgren et al., 1983 and Proctor et al., 1975). In a recent in vivo study, neutrophils were recruited in a dose-dependent fashion; however, neither neutrophil depletion nor enhancement of early recruitment affected either bacterial burdens in the mouse lung or survival times following F. tularensis (type A) SCHU S4 infection with NADPH oxidase playing only a minor role in host defense (KuoLee et al., 2011). These findings are in contrast to those of Conlan and Lindgren indicating neutrophils as well as the NADPH dependent phagocyte oxidase to be critical for host defense against systemic F. tularensis LVS infection (Conlan et al., 2002; Lindgren et al., 2004).

Although examination of the orchestrated shaping of the host defense immune response to Francisella has lead to conflicting reports, the interaction of neutrophil elastase, $\alpha_{1}$-antitrypsin, and possible involvement of other proteinases is consistent with the theme of unchecked elastase activity, i.e., $\alpha_{1}$-antitrypsin reduction/clearance. For example, in response to neutrophil elastase, macrophages produce IL-8, matrix metalloprotease-2, and cathep$\sin \mathrm{B}$; proteins that typically promote chemotaxis (Geraghty et al., 2007). Using an in vivo model of acute lung injury, Ferry et al. (1997) suggested neutrophil elastase to be a physiological activator of matrix metalloprotease-9. Subsequently, Malik et al. (2007) demonstrated matrix metalloproteinase-9 activity to enhance host susceptibility to pulmonary infection with types A and B strains of F. tularensis. This finding was consistent with an earlier observation by Liu et al. (2000) indicating $\alpha_{1}$-antitrysin was recognized as a degradative substrate by gelatinase $B$ metalloproteinase- 9 , cleavage of which indirectly enhances further neutrophil elastase activity generating $\alpha_{1}$-antitrysin peptide fragments that have neutrophil-chemotactic activity.

Both $\alpha_{1}$-antitrypsin and haptoglobin are major participants in the evolutionarily conserved acute phase response. In this report, we describe significant reduction of $\alpha_{1}$-antitrysin, the major inhibitor of extracellular neutrophil elastase in plasma of $F$. tularensis LVS and F. tularensis (type A) SCHU S4 strain infected animals with a concomitant increase in haptoglobin, the major acute phase hemoglobin-binding protein in the plasma of most vertebrates and all mammals (Wicher and Fries, 2006) supporting the competent nature of the acute phase response in infected animals. We suggest that following infection by $F$. tularensis, plasma $\alpha_{1}$-antitrypsin is preferentially reduced leading to directly and/or indirectly via possible involvement of other proteases (1) clearance of $\alpha_{1}$-antitrysin in the plasma and (2) unchecked lung lavage fluid neutrophil elastase activity thus promoting lung tissue damage and increased dissemination of this bacterium from the lungs to other tissues.

\section{MATERIALS AND METHODS BACTERIAL STRAINS}

Studies described in this report utilized F. tularensis LVS and F. tularensis subsp. tularensis (type A) SCHU S4 strain. Bacteria were grown at $37^{\circ} \mathrm{C}$ in trypticase soy broth (TSB) or on trypticase soy agar (TSA) each supplemented with $0.1 \%$ cysteine for $24-48 \mathrm{~h}$.

\section{MICE}

Four to six-week-old female C57BL/6 mice were obtained from Charles River Laboratories (Frederick, MD, USA). Mice were housed at the University of Texas at San Antonio animal facility and all experimental procedures were performed in compliance with the Institutional Animal Care and Use Committee (IACUC) guidelines.

\section{INTRANASAL (I.N.) CHALLENGE}

Mice were first anesthetized with 3\% isoflurane using a rodent anesthesia system (Harvard Apparatus, Holliston, MA, USA) followed by inoculation i.n. with either $5000 \mathrm{CFU}$ F. tularensis LVS, 50 CFU F. tularensis (type A) SCHU S4, or mock (PBS-treated) control.

\section{PREPARATION OF PLASMA}

Mice (5) in each respective group, i.e., Mock (PBS-treated) control, F. tularensis LVS, and F. tularensis (type A) SCHU S4 were bled $72 \mathrm{~h}$ post i.n. challenge and plasma prepared using plasma collection tubes containing lithium heparin and polymer gel (BD Bioscience, NJ, USA). Respective plasma samples were centrifuged for $5 \mathrm{~min}$ at $5000 \mathrm{rpm}$ and supernatant (plasma) was removed and stored at $-20^{\circ} \mathrm{C}$ until used. The respective plasmas were assayed individually.

\section{PREPARATION OF LUNG LAVAGE AND ELASTASE DETERMINATION}

For collection of bronchoalveolar lavage fluid, five mice (5-day post challenge) from all three groups, i.e., Mock (PBS-treated) control, F. tularensis LVS, and F. tularensis (type A) SCHU S4 infected animals were sacrificed and the trachea intubated using a $0.58 \mathrm{~mm}$ (outside diameter) polyethylene catheter (Becton Dickinson, Sparks, MD, USA). Lungs were lavaged twice with Hanks balanced salt solution (Invitrogen, Carlsbad, CA, USA). Recovered fluid $(1 \mathrm{ml})$ was centrifuged at $9,500 \times g$ for $7 \mathrm{~min}$ at $5^{\circ} \mathrm{C}$ and the supernatant was stored at $-70^{\circ} \mathrm{C}$ until used. Each lavage fluid sample was assayed fluorometrically in triplicate for elastase activity using $0.1 \mathrm{mM}$ suc-ala-ala-ala-MCA substrate (Peptide Institute, Inc., Osaka, Japan) dissolved in $0.05 \mathrm{M}$ Tris- $\mathrm{HCl}$ 
buffer, $\mathrm{pH} 7.5$ in a final reaction volume of $1 \mathrm{ml}$ for $48 \mathrm{~h}$ at $37^{\circ} \mathrm{C}$. Purified elastase (Sigma Chemical Company, St. Louis, MO, USA) served as control. Hydrolysis of substrate was extrapolated to a 7-amino-4-methylcoumarin standard curve. Purified elastase (1 Unit) was observed to liberate $1.84 \mu \mathrm{moles} / \mathrm{ml} / \mathrm{h}$. Lavage elastase activity is expressed as nmoles/ml lavage material/h.

\section{DETERMINATION OF PLASMA ALPHA-1 ANTITRYPSIN CONTENT}

The concentration of $\alpha_{1}$-antitrypsin in the plasma of each animal of the respective groups was determined by ELISA using a mouse $\alpha_{1}$-antitrypsin ELISA Kit (Kamiya Biochemical Company) per manufacturer's instructions.

\section{ASSESSMENT OF RESPIRATORY MECHANICS}

Lung tissue hysteresivity and elastance were assessed 5-days post i.n. challenge. Briefly, mice were anesthetized and given an intraperitoneal injection of muscle relaxant (pancuronium bromide). Mock (PBS-treated) controls and F. tularensis LVS infected animals were intubated and mechanically ventilated by a computer controlled piston ventilator (FlexiVent, SCIREQ, Montreal, QC, Canada). Lung function analyses were carried out using pressurevolume loops by inflating mice at various increments of pressure until a maximum pressure of $33 \mathrm{~mm} \mathrm{Hg}\left(25 \mathrm{~cm} \mathrm{H}_{2} \mathrm{O}\right)$. Deflation was achieved by step-wise decrements of pressure at corresponding intervals. Anesthetized mice were mechanically ventilated with a tidal volume of $10 \mathrm{ml} / \mathrm{kg}$ and a frequency of $2.5 \mathrm{~Hz}$. Resistance data were collected using a single compartment model and the derived data plotted following normalization to percent base line resistance/compliance.

\section{TWO DIMENSIONAL PAGE AND MASS SPECTROMETRY ANALYSIS}

Two dimensional PAGE analyses were carried out on different plasmas of each respective group using BioRad Ready Prep Reagents/gels (Hercules, CA, USA) per manufacturer's instructions. Respective mouse plasmas $(150 \mu \mathrm{l})$ were separated in the first dimension using $\mathrm{pH}$ 4-7 Ready Strip IPG strips and in the second dimension on $8-16 \%$ precast SDS Ready Gels. Gels were stained with SYPRO Ruby (Invitrogen/Molecular Probes, Inc., Eugene, OR, USA) according to the manufacturer's rapid staining protocol. Gel spots of interest were excised, digested in situ with trypsin (Trypsin Profile IGD Kit; Sigma Chemical Co., St. Louis, MO, USA) and the resulting peptides analyzed by capillary HPLC-electrospray ionization tandem mass spectrometry (HPLC-ESI-MS/MS) on a Thermo Fisher LTQ mass spectrometer. The tandem mass spectra were searched against the Swiss-Prot database by means of Mascot (Matrix assessment of probabilities of peptide and protein assignments by Scaffold, Proteome Software, Portland, OR, USA). The significance thresholds for peptide and protein assignments were 95 and 99\%, respectively with a minimum of two peptides required for protein identification.

\section{STATISTICAL ANALYSES}

Data were evaluated using the Student's $t$-test (SigmaStat statistical software program) and are presented as the mean value \pm SD. The number of replicates for each experiment is indicated in the respective figure legends.

\section{RESULTS \\ FRANCISELLA INFECTION RESULTED IN MARKEDLY DECREASED PLASMA $\alpha_{1}$-ANTITRYPSIN ACCOMPANIED BY A CONCOMITANT INCREASE IN HAPTOGLOBIN ( $\beta$-CHAINS)}

Mice are highly susceptible to Francisella infection and have been used widely as an animal model to study tularemia disease. In order to study the acute phase response, we challenged mice intranasally with a lethal dose of F. tularensis LVS or F. tularensis (type A) SCHU S4 strain and collected plasma at 3-days post-challenge for protein profile comparison to a similarly prepared plasma from mock (PBS-treated) mice using two dimensional gel/proteomic analyses. Shown in Figure $\mathbf{1}$ are representative images of three different two-dimensional gel electrophoresis experiments. A significantly different protein profile was observed for mock (PBS-treated) plasma compared to F. tularensis LVS and F. tularensis (type A) SCHU S4 infected plasma exhibiting (1) a significant decrease in a protein of approximate $50 \mathrm{kDa}$ molecular weight, and (2) a significant increase in a protein of approximate $40 \mathrm{kDa}$ molecular weight. These proteins were identified as $\alpha_{1}$-antitrypsin (charge train 1) and haptoglobin $\beta$-chains (charge train 2) by tandem mass spectrometry. Charge heterogeneity in both $\alpha_{1}$-antitrypsin and haptoglobin $\beta$-chains arises from differing sialic acid content of the $N$-type glycosides (Mega et al., 1980; Park et al., 2010). Haptoglobin like $\alpha_{1}$-antitrypsin is a major participant/member of the evolutionarily conserved set of acute phase plasma proteins.

In order to further corroborate the two dimensional gel analysis, $\alpha_{1}$-antitrypsin content in plasma of mock (PBS-treated) controls and 3-day post challenge Francisella infected animals was determined. Although less than the expected almost complete removal of $\alpha_{1}$-antitrypsin shown in Figure 1, a 25\% reduction

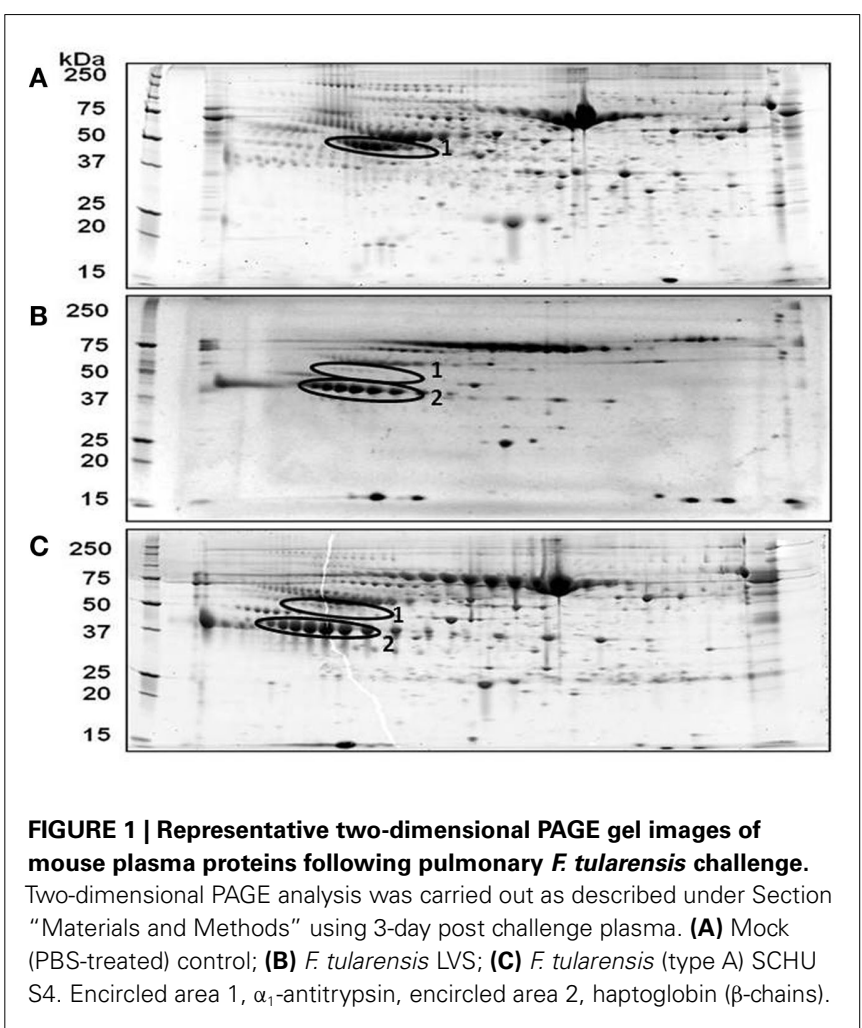


in plasma $\alpha_{1}$-antitrypsin level was observed in F. tularensis LVS $(6.8 \pm 1.2 \mathrm{mg} / \mathrm{ml})$ infected animals compared to the mock (PBStreated) control $(9.1 \pm 0.5 \mathrm{mg} / \mathrm{ml}$, Figure 2$)$. Mice infected with F. tularensis (type A) SCHU S4 strain $(3.2 \pm 0.4 \mathrm{mg} / \mathrm{ml})$ exhibited a $65 \%$ reduction of plasma $\alpha_{1}$-antitrypsin, an approximate 2.6 fold greater reduction than that observed for LVS infected animals (Figure 2).

\section{LUNG ELASTASE ACTIVITY WAS INCREASED IN FRANCISELLA INFECTED ANIMALS}

Neutrophil elastase is capable of digesting the underlying elastin structure of the alveolar walls (Janoff, 1985). Normally, neutrophil elastase-mediated damage is suppressed by $\alpha_{1}$-antitrypsin (Carrell, 1986). Since $\alpha_{1}$-antitrypsin was significantly reduced upon Francisella infection, we examined elastase activity residing at the primary infection site, i.e., lungs, 3-days after intranasal F. tularensis LVS and F. tularensis (type A) SCHU S4 challenge. Consistent with decreased levels of plasma and lung lavage $\alpha_{1}$-antitrypsin, a 1.9-fold increase in respiratory lavage fluid elastase activity was observed following F. tularensis challenge (Figure 3).

\section{LUNG TISSUE ELASTANCE WAS REDUCED IN FRANCISELLA INFECTED ANIMALS}

Examination of lung function following F. tularensis LVS infection indicated lung tissue elastance to be reduced $24 \%$ with a concomitant $24 \%$ increase in the tissue hysteresivity ratio compared to the mock (PBS-treated) control (Figure 4). Assessment of lung function following F. tularensis (type A) SCHU S4 challenge could not be performed under required BSL-3 containment conditions.

\section{DISCUSSION}

Serpins compose the largest super family of peptidase inhibitors and are well known as regulators of hemostasis and thrombolysis. Acute phase proteins are generally viewed as being relevant in providing protective functions at sites of tissue injury such as containment of tissue degradation, facilitation of wound healing, and

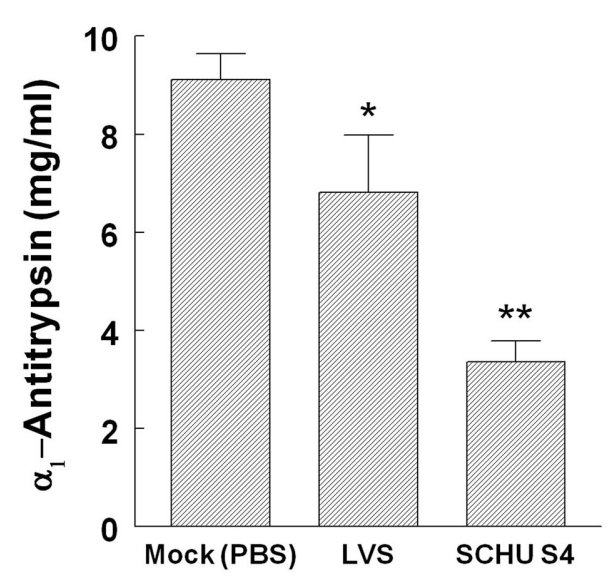

FIGURE 2 | Decreased plasma $\alpha 1$-antitrypsin following pulmonary F tularensis challenge. Mouse plasma $\alpha_{1}$-antitrypsin content was determined using 3-day post challenge plasma from each animal ( $n=5 /$ group) as described under Section "Materials and Methods" ${ }^{*}=p<0.05 ;{ }^{*}=p<0.005$. restoration of homeostasis. Alpha-1 antitrypsin, an acute phase protein has been shown to increase in humans following bacterial and viral infection (Bini et al., 1996; Zhang et al., 2010) using both in vivo and in vitro models (Pineiro et al., 2004). However, to the best of our knowledge, the reduction of the major extracellular serpine, i.e., $\alpha_{1}$-antitrypsin in plasma has not been described.

Comparison of two dimensional gel plasma protein profiles of mock (PBS-treated) control and infected animals indicate a significant reduction of plasma $\alpha_{1}$-antitrypsin following pulmonary challenge with F. tularensis LVS and F. tularensis (type A) SCHU S4. Haptoglobin also an acute phase protein was observed to increase markedly in intensity ( $\beta$-chains) following infection supporting

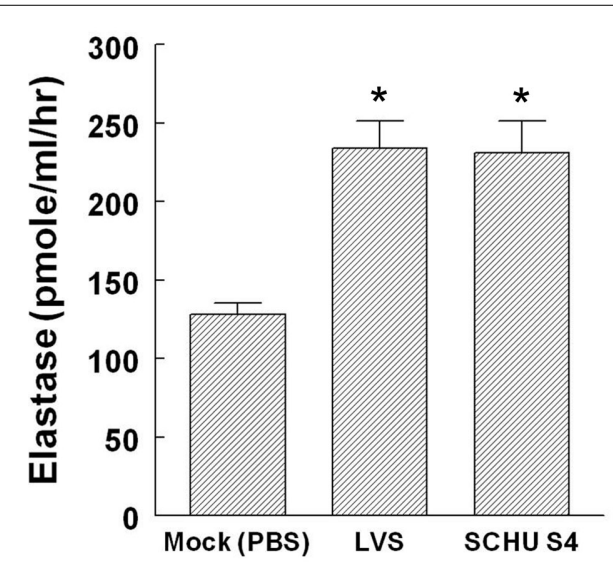

FIGURE 3 | Increased elastase activity in respiratory fluids following pulmonary $\boldsymbol{F}$ tularensis challenge. Bronchoalveolar lavage fluid from mice (5-day post challenge, $n=5$ /group) from each group, i.e., Mock (PBS-treated) control, F. tularensis LVS, and F. tularensis (type A) SCHU S4 infected animals was prepared and assayed for elastase activity in triplicate as described under Section "Materials and Methods" ${ }^{* *}=p<0.05$

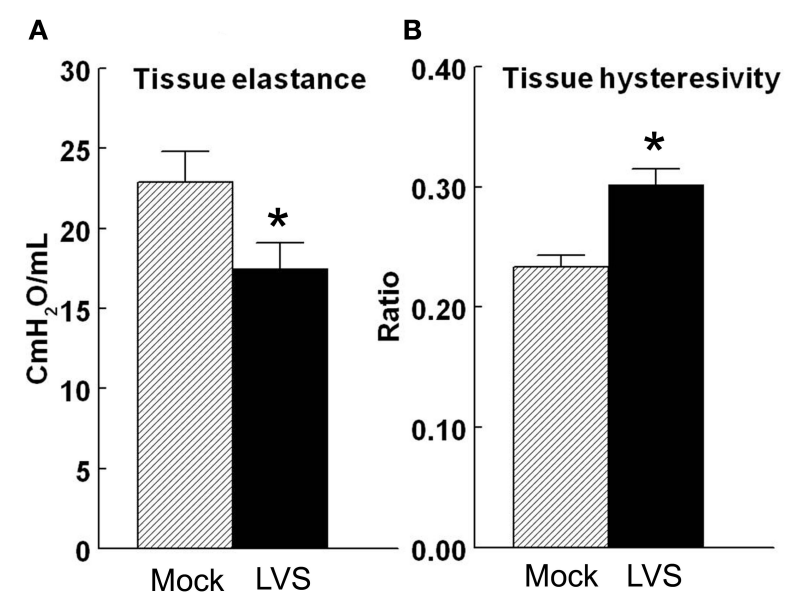

FIGURE 4 | Effects of $\boldsymbol{F}$. tularensis LVS infection on lung tissue functions. Lung tissue function (elastance and hysteresivity) was determined using 5-day post challenge animals ( $n=5 /$ group) as described under Section "Materials and Methods." (A) Tissue Elastance; (B) Tissue Hysteresivity ${ }^{*}=p<0.05$ 
the competent nature of the acute phase response in infected animals. Haptoglobin's hepatic expression is strongly induced by inflammatory mediators such as cytokines which are known to be critical for immune-regulation, increasing within $24 \mathrm{~h}$ the haptoglobin plasma concentration from as low as $<50 \mu \mathrm{gm} / \mathrm{ml}$ to $\sim 2.5 \mathrm{mg} / \mathrm{ml}$ (Huntoon et al., 2008). Quantitative ELISA analyses corroborated reduced levels of plasma $\alpha_{1}$-antitrypsin although the percent decrease observed for F. tularensis LVS and F. tularensis (type A) SCHU S4 infected animals was significantly different. In contrast to the ELISA data, the increase in lung lavage elastase activity for both F. tularensis LVS and F. tularensis (type A) SCHU S4 was the same, i.e., 1.9-fold following infection. The incongruity between plasma ELISA data and increased elastase enzyme activity of lung lavage fluid in all likelihood arises from partial proteolytic clipping/destruction of anti $\alpha_{1}$-antitrypsin specific epitopes in the respective plasmas which stoichiometrically is unrelated to the lung lavage elastase pool activity. Examination of respective F. tularensis LVS and F. tularensis (type A) SCHU S4 2D PAGE protein profiles indicate a generalized clearing of the plasma $\alpha_{1}$-antitrypsin consistent with extensive proteolytic degradation. Due to the lung lavage fluid elastase pool being much smaller and restricted in locale, i.e., non-circulating compared to that of plasma $\alpha_{1}$-antitrypsin, the fold increase in lung lavage fluid elastase activity would be expected to exhibit little variation. Additionally, the observed range of plasma $\alpha_{1}$-antitrypsin values for F. tularensis (type A) SCHU S4 treated animals is considerably smaller, i.e., tighter (mean value $\pm 0.4 \mathrm{mg} / \mathrm{ml}, n=5$ ) compared to that of plasma obtained from animals treated with $F$. tularensis LVS (mean $\pm 1.2 \mathrm{mg} / \mathrm{ml}, n=5$ ). The difference in plasma $\alpha_{1}$ antitrypsin content could arise from the more virulent nature of F. tularensis (type A) SCHU S4; however, this remains to be established. Consistent with the primary protective function of $\alpha_{1}$-antitrypsin, imbalance of the protease-antiprotease function at the alveolar level in the lungs of infected animals and concomitant increase in lung lavage fluid elastase activity was associated with decreased lung function, i.e., loss of lung elastance with concomitant increase of pulmonary hysteresivity (Stockley, 1983, 1987).

\section{REFERENCES}

Belaaouaj, A. A., McCarthy, R., Baumann, M., Gao, Z., Ley, T. J., Abraham, S. N., and Shapiro, S. D. (1998). Mice lacking neutrophil elastase reveal impaired host defense against gram negative bacterial sepsis. Nat. Med. 4, 615-618.

Bini, L., Magi, B., Marzocchi, B., Cellesi, C., Berti, B., Raggiaschi, R., Rossolini, A., and Pallini, V. (1996). Two-dimensional electrophoretic patterns of acutephase human serum proteins in the course of bacterial and viral diseases. Electrophoresis 17, 612-616.

Carrell, R. W. (1986). Alpha 1antitrypsin: molecular pathology,

It is well-established that Francisella enters and replicates intracellularly. However, a recent study by Forestal et al. (2007) indicated greater than $50 \%$ of extracellular $F$. tularensis LVS and $F$. tularensis (type A) SCHU S4 is found in the plasma of mice infected intradermally or intranasally. Subsequently, Yu et al. (2008) demonstrated that intranasal F. novicida challenge resulted in highly infectious Francisella in plasma and proposed that this may be a contributing factor in the rapid dissemination of the bacterium from lungs to the liver after pulmonary infection. Within the respiratory system, distinct mechanisms contribute to innate defenses in the airways and alveolar spaces. Mucociliary clearance predominates in the airways; whereas, phagocytic cells such as macrophages and neutrophils are involved in removal of microorganisms that reach the deeper alveolar spaces (Pilette et al., 2001). Activation of toll-like receptor (TLR)-2 signaling in phagocytic cells and matrix metalloproteinase- 9 activity have been reported and suggested to be important in defense against pulmonary infection with Francisella as evidenced by increased bacterial burden and enhanced susceptibility in knockout animals (Malik et al., 2006, 2007). In light of the competent nature of the acute phase response to Francisella, data presented here suggest preferential clearance of $\alpha_{1}$-antitrypsin from the plasma of infected animals. Although decreased levels of $\alpha_{1}$-antitrypsin in lung lavage material is consistent with increased levels of alveolar neutrophil elastase activity and tissue destruction promoting dissemination of the bacterium, the role of other proteolytic participants in this process, e.g., matrix metalloproteinases cannot be ruled out thus warranting further investigation.

\section{ACKNOWLEDGMENTS}

This material is based upon the work supported by the Army Research Office of the Department of Defense under Contract No. W911NF-11-1-0136, SALSI Grant 14-3300-24, and National Institutes of Health, PO1 AI057986. Mass spectrometry analyses were conducted at the Institutional Mass Spectrometry Laboratory of the University of Texas Health Science Center at San Antonio.

by neutrophil elastase in an in vivo model of acute lung injury. FEBS Lett. 402, 111-115.

Forestal, C. A., Malik, M., Catlett, S. V., Savitt, A. G., Benach, J. L., Sellati, T. J., and Furie, M. B. (2007). Francisella tularensis has a significant extracellular phase in infected mice. J. Infect. Dis. 196, 134-147.

Garcia, R., Gusmani, L., Murgia, R., Guarnaccia, C., Cinco, M., and Rottini, G. (1998). Elastase is the only human neutrophil granule protein that alone is responsible for the in vitro killing of Borrelia burgdoferi. Infect. Immun. 66, 1408-1412.

Geraghty, P., Rogan, M. P., Greene, C. M., Boxio, R. M., Poiriert, T., O’Mahony, M., Belaaouaj, A., O'Neill, S. J., Taggart, C. C., and
McElvaney, N. G. (2007). Neutrophil elastase up-regulates cathepsin B and matrix metalloprotease-2 expression. J. Immun. 178, 5871-5878.

Heutinck, K. M., Ten Berge, I. J., Hack, C. E., Hamann, J., and Rowshani, A. T. (2010). Serine proteases of the human immune system in health and disease. Mol. Immunol. 47, 1943-1955.

Huntoon, K. M., Wang, Y., Eppolito, C. A., Barbour, K. W., Berger, F. G. Shrikant, P. A., and Baumann, H. (2008). The acute phase protein haptoglobin regulates host immunity. $J$. Leukoc. Biol. 84, 170-181.

Janoff, A. (1985). Elastase in tissue injury. Annu. Rev. Med. 36, 207-216. 
Kielty, C. M., Lees, M., Shuttleworth, C. A., and Woolley, D. (1993). Catabolism of intact type VI collagen microfibrils: susceptibility to degradation by serine proteinases. Biochem. Biophys. Res. Commun. 191, 1230-1236.

KuoLee, R., Harris, G., Conlan, J. W., and Chen, W. (2011). Role of neutrophils and NADPH phagocyte oxidase in host defense against respiratory infection with virulent Francisella tularensis in mice. Microbes Infect. 13, 447-456.

Lindgren, H., Stenmark, S., Chen, W., Tarnvik, A., and Sjostedt, A. (2004). Distinct roles of reactive nitrogen and oxygen speciies to control infection with the faculative intracellular bacterium Francisella tularensis. Infect. Immun. 72, 7172-7182.

Liu, Z., Zhou, X., Shapiro, S. D., Shipley, J. M., Twining, S. S., Diaz, L. A., Senior, R. M., and Werb, Z. (2000). The serpin alpha-1proteinase inhibitor is a critical substrate for gelatinase B/MMP in vivo. Cell 102, 647-655.

Lofgren, S., Tarnvik, A., Bloom, G. D., and Sjoberg, W. (1983). Phagocytosis and killing of Francisella tularensis by human polymorphonuclear leukocytes. Infect. Immun. 39, 715-720.

Malik, M., Bakshi, C. S., McCabe, K., Catlett, S. V., Shah, A., Singh, R., Jackson, P. L., Gaggar, A., Metzger, D. W., Melendez, J. A., Blalock, J. E., and Sellati, T. J. (2007). Matrix Metalloproteinase 9 activity enhances host susceptibility to pulmonary infection with Tpe A and B strains of Francisella tularensis. J. Immunol. 178, 1013-1020.

Malik, M., Bakshi, C. S., Sahay, B., Shah, A., Lotz, S. A., and Sellati, T. J. (2006). Toll-like receptor 2 is required for control of pulmonary infection with
Francisella tularensis. Infect. Immun. 74, 3657-3662.

Mega, T., Lujan, E., and Yoshida, A. (1980). Studies on the oligosaccharide chains of human $\alpha 1$ protease inhibitor. II. Structure of oligosaccharides. J. Biol. Chem. 255, 4057-4061.

Methot, N., Rubin, J., Guay, D., Beaulieu, C., Ethier, D., Reddy, T.J., Riendeau, D., and Percival, M.D. (2007). Inhibition of the activation of multiple serine proteases with a cathepsin C inhibitor requires sustained exposure to prevent pro-enzyme processing. J. Biol. Chem. 282, 20836-20846.

Mezyk-Kopec, R., Bzowska, M., Bzowska, M., Mickowska, B., Mak, P., Potempa, J., and Bereta, J. (2005). Effects of elastase and cathepsin $\mathrm{G}$ on the levels of membrane and soluble TNFalpha. Biol. Chem. 386, 801-811.

Moreland, J., Hook, J., Bailey, G., Ulland, T., and Nauseef, W. (2009). Francisella tularensis directly interacts with the endothelium and recruits neutrophils with a blunted inflammatory phenotype. Am. J. Physiol. Lung Cell. Mol. Physiol. 296, L1076L1084.

Park, S.-Y., Yoon, S.-J., Jeong, Y.T., Kim, J.-M., Kim, J.-Y., Bernert, B., Ullman, T., Itzkowitz, S. H., Kim, J.-H., and Hakamori, S. (2010). $N$-glycosylation status of $\beta$ haptoglobin in sera of patients with colon cancer, chronic inflammatory diseases and normal subjects. Int. J. Cancer 126, 142-155.

Pilette, C., Quadrhiri, Y., Godding, V., Vaerman, J. P., and Sibile, Y. (2001). Lung mucosal immunity: immunoglobulin-a revisit. Eur. Respir. J. 18, 571-588.

Pineiro, M., Andres, M., Iturralde, M., Carmona, S., Hirvonen, J., Pyorala,
S., Heegaard, P.M., Tjornehoj, K., Lampreave, F., Pineiro, A. and Alava, M.A. (2004). ITIH4 (inter-alphatrypsin inhibitor heavy chain 4) is a new acute-phase protein isolated from cattle during experimental infection. Infect. Immun. 72, 3777-3782.

Proctor, R. A., White, J. D., Ayala, E., and Canonico, P. G. (1975). Phagocytosis of Francisella tularensis by rhesus monkey peripheral leukocytes. Infect. Immun. 11, 146-151.

Schricker, R. L., Eigelsbach, H. T., Mitten, J. Q., and Hall, W. C. (1972). Pathogenesis of tularemia in monkeys aerogenically exposed to Francisella tularensis 425. Infect. Immun. 5, 734-744.

Stockley, R. A. (1983). Proteolytic enzymes, their inhibitors and lung diseases. Clin. Sci. (Lond.) 64, 119-126.

Stockley, R. A. (1987). Alpha-1antitrypsin and the pathogenesis of emphysema. Lung 165, 61-77.

Stuart, B. M., and Pullen, R. L. (1945). Tularemic pneumonia: review of American literature and report of 15 additional cases. Am. J. Med. Sci. 210 , 223-236.

Tkalcevic, J., Novelli, M., Phylactides, M., Iredale, J. P., Segal, A. W. and Roes, J. (2000). Impaired immunity and enhanced resistance to endotoxin in the absence of neutrophil elastase and cathepsin G. Immunity 12, 201-210.

Travis, J. (1988). Structure, function, and control of neutrophil proteinases. Am. J. Med. 84, 37-42.

Weinrauch, Y., Drujan, D., Shapiro, S. D., Weiss, J. and Zychlinsky, A. (2002). Neutrophil elastase targets virulence factors of enterobacteria. Nature 417, 91-94.

Wicher, K. B., and Fries, E. (2006). Haptoglobin, a hemoglobin-binding plasma protein is present in bony fish and mammals but not in frog and chicken. Proc. Natl. Acad. Sci. U.S.A. 103, 4168-4173.

Yu, J. J., Raulie, E. K., Murthy, A. K., Guentzel, M. N., Klose, K. E. and Arulanandam, B. P. (2008). The presence of infectious extracellular Francisella tularensis subsp. novicida in murine plasma after pulmonary challenge. Eur. J. Clin. Microbiol. Infect. Dis. 27, 323-335.

Zhang, L., Jia, X., Zhang, X., Cao, J., Yang, P., Qiu, C., Shen, Y., Ma, R., Liu, L., Sun, J., Shen, F., Yin, L., Yao, Y., and Lu, H. (2010). Alpha-1 antitrypsin variants in plasma from HIV-infected patients revealed by proteomic and glycoproteomic analysis. Electrophoresis 31, 3437-3445.

Conflict of Interest Statement: The authors declare that the research was conducted in the absence of any commercial or financial relationships that could be construed as a potential conflict of interest.

Received: 05 August 2011; accepted: 05 December 2011; published online: 26 December 2011.

Citation: Chambers JP, Yu J-J, Jupelli $M$, Weintraub ST, Lopez-Ribot JL, Valdes $J J$ and Arulanandam BP (2011) Alpha1 antitrypsin is markedly decreased following pulmonary F. tularensis challenge. Front. Cell. Inf. Microbio. 1:20. doi: 10.3389/fcimb.2011.00020

Copyright () 2011 Chambers, Yu, Jupelli, Weintraub, Lopez-Ribot, Valdes and Arulanandam. This is an open-access article distributed under the terms of the Creative Commons Attribution Non Commercial License, which permits noncommercial use, distribution, and reproduction in other forums, provided the original authors and source are credited. 